\title{
Acid Leaching Tests on a Highly Oxidized Copper Ore in Yunnan
}

\author{
Yang Zhao ${ }^{1, a}$ \\ ${ }^{1}$ Faculty of Land Resource Engineering, Kunming \\ University of Science and Technology \\ Kunming, China \\ azhaoyang5411@126.com, \\ Siqing $\mathrm{Liu}^{2, \mathrm{~b}}$ \\ ${ }^{2}$ State Key Laboratory of Complex Nonferrous \\ Metal Resources Clean Utilization \\ b647647@qq.com \\ Tingting Li1,e \\ ${ }^{1}$ Faculty of Land Resource Engineering, Kunming \\ University of Science and Technology \\ Kunming, China \\ e657319773@qq.com
}

\begin{abstract}
The extraction of copper from highly oxidized copper ore in sulfuric acid solutions was examined in Yunnan Province. During the leaching of copper, the leaching rate of cuprous concentration was affected by various parameters such as particle size, leaching time, the weight ratio of liquid to solid and the consumption of sulfuric acid, etc. Through a series of tests, the results show that leaching rate of copper reaches more than $90 \%$ by means of sulfuric acid under the best conditions which are particle size of $-1 \mathrm{~mm}$, the leaching time of $3 \mathrm{~h}$, the liquid-solid weight ratio of $4: 1$, the weight ratio of ore to sulfuric acid of 1:0.4 at normal temperature and pressure.
\end{abstract}

Keywords-high oxidation rate; copper ore; sulfuric acid; leaching; Yunnan;

\section{INTRODUCTION}

Copper is a kind of strategic non-ferrous metal resources, it plays an important role in the modern society. Copper is widely used in electrical \& electronics, energy, petrochemical, transportation, mechanical metallurgy and national defense and so on. Copper ore and its concentrate is the main raw material of metallurgical industry. Sulfide (chalcopyrite, chalcocite) are primary source of copper. Due to rapid economic growth, there has been a tremendous demand for copper. However, we are facing with the shortage of copper. Copper ore is classify in accordance with the oxidation rate, including sulfide ores (oxidation rate $<10 \%$ ) and oxidized ore (oxidation rate $>30 \%$ ) and mixed ore (oxidation rate is between $10 \%-30 \%$ ). Statistics show that oxide copper ore and mixed copper ore account for about $10 \%-15 \%$ of the world's copper resources, the amount of copper metal of the two kinds of copper ore accounts for about $25 \%$ of the total reserves of copper. The copper ore we exploited has some disadvantages, such as low grade, complex minerals

\author{
Dan Wang ${ }^{1, \mathrm{c}}$ \\ ${ }^{1}$ Faculty of Land Resource Engineering, Kunming \\ University of Science and Technology \\ Kunming, China \\ c1259663813@qq.com \\ Hailin Liu ${ }^{1, \mathrm{~d}}$ \\ ${ }^{1}$ Faculty of Land Resource Engineering, Kunming \\ University of Science and Technology \\ Kunming, China \\ d1036412583@qq.com
}

composition and high oxidation rate. Therefore, the study of the refractory copper ore has been extensively investigated. Leading-solventextraction-electrowinning has been successfully used for the low grade and high oxidation rate copper ore. The ore we used is high oxidation rate and the gangue is acid. Therefore, the acid leaching is suitable for the ore.

\section{MATERIALS}

After crushing the ore, it is observed that associated minerals were mainly primary slime which was formed by alteration of wall rock and gangue, kaolin, bentonite, talc, and goethite. Copper oxide exists in the form of malachite, azurite and cuprite. The copper grade of the ore is about $2.42 \%$. Results of the multi-element chemical analysis and copper ore phase analysis of the sample are shown in Table 1 and Table 2, respectively. According to the results of the analysis in Table 1 and Table 2, copper is valuable element of the ore. Silver is associated element, which can be concentrated comprehensively by enriching in copper concentrate. As to the sample, the oxidation rate reaches up to $86.36 \%$, the ore is a typical copper oxide ore.

TABLE I RESULT OF CHEMICAL ANALYSIS OF THE SAMPLE $\left({ }^{*} \mathrm{G} / \mathrm{T}\right)$

\begin{tabular}{ccccccccccc}
\hline Eleme & $\boldsymbol{C}$ & $\boldsymbol{S}$ & $\boldsymbol{P}$ & $\boldsymbol{Z}$ & $\boldsymbol{A}$ & $\boldsymbol{S}$ & $\boldsymbol{F}$ & $\boldsymbol{A}$ & $\boldsymbol{S}$ & $\boldsymbol{C}$ \\
$\boldsymbol{n t}$ & $\boldsymbol{u}$ & $\boldsymbol{b}$ & $\boldsymbol{b}$ & $\boldsymbol{n}$ & $\boldsymbol{g}^{*}$ & & $\boldsymbol{e}$ & $\boldsymbol{u}^{*}$ & & $\boldsymbol{a}$ \\
\hline \multirow{2}{*}{ Conte } & 2. & 0. & 0. & 0. & 13 & 21 & 5. & & 0. & 5. \\
$\boldsymbol{n t} / \%$ & 4 & 3 & 7 & 7 & 5. & .5 & 4 & 0. & 6 & 2 \\
& 2 & 1 & 1 & 8 & 6 & 7 & 2 & & 8 & 6 \\
\hline
\end{tabular}


TABLE II ANALYSIS RESULTS OF COPPER PHASE IN ORE SAMPLE

\begin{tabular}{cccc}
\hline Phase & $\begin{array}{c}\text { Copper in the } \\
\text { copper oxide }\end{array}$ & $\begin{array}{c}\text { Copper in the } \\
\text { copper sulfide }\end{array}$ & $\begin{array}{c}\text { Total } \\
\text { copper }\end{array}$ \\
\hline Occupation/\% & 2.09 & 0.33 & 2.42 \\
\hline
\end{tabular}

\section{LEACHING EXPERIMENTS}

In the laboratory scale tests, the effects of different parameters such as grinding duration, leaching time, liquid-solid ratio and the ore to sulfuric acid weight ratio were investigated in relation to the metals contents and recoveries of concentrates. The leaching experiments were undertaken in a ZHWY-100B type biological shaking table and the shaking speed was $140 \mathrm{r} / \mathrm{min}$. The leaching temperature is normal temperature. The grinding concentration is $33 \%$

\section{A. Test of grinding fineness}

The cost of grinding account for most of the cost of mineral processing. In order to try our best to reduce the cost of mineral processing, finding the proper grinding time is an important means. Therefore, tests of grinding fineness were conducted in the small laboratory with a XMQ-250×450 type conical ball mill. The grinding concentration is $33 \%$. Results of grinding fineness tests are shown in the Fig.1.

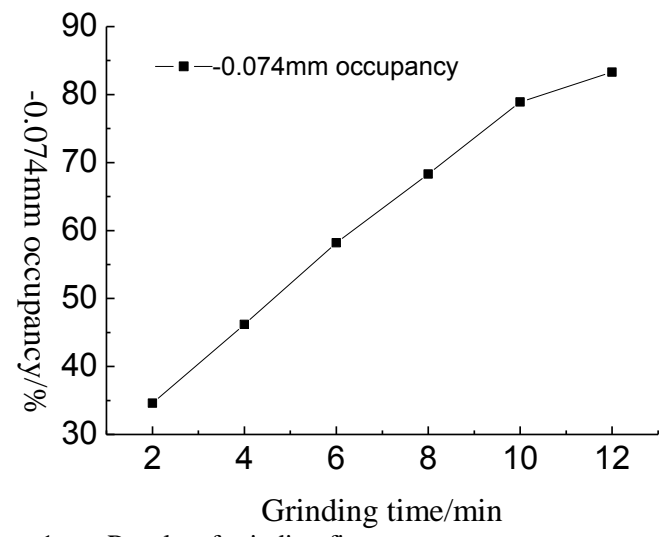

Figure 1. Results of grinding fineness tests

It is shown in Fig .1 that, under the same test conditions, the grinding fineness gradually increased with the increasing of grinding time. When the grinding time is 6 min, the $58.2 \%$ grinding fineness can be obtained. The grinding fineness is $78.9 \%$ in the case of 10 min grinding time. It can be deduced from these results that the ore belongs to medium-hard and is easy to be ground. Grinding classification need to be noticed to prevent overgrinding.

\section{B. Effect of grinding fineness}

Because most minerals are finely disseminated and intimately associated with the gangue minerals, they must be initially "unlocked" or "liberated" before separation can be undertaken. The effective liberation of copper and gangue is the foundation of getting copper separated. Thus the effect of grinding duration on leaching experiments was investigated, and results are shown in Fig .2. The leaching time was $3 \mathrm{~h}$, the liquid-solid ratio and the ore to sulfuric acid weight ratio were $4: 1$ and $1: 0.4$, respectively.

According to the result shown in Fig .2, under the same leaching conditions, the grinding fineness little effects on the leaching of copper. The grinding fineness of $20 \%$ and $80 \%$ get the leaching rate of $89.35 \%$ and $90.66 \%$, respectively. Taking into account the high cost of grinding, grinding is unnecessary. The ore that size is $-1 \mathrm{~mm}$ is used to leach directly.

\section{Effect of leaching time}

The proper leaching time is also a means of saving cost. Meanwhile, shorter leaching time helps to improve production efficiency. However, if the leaching time is too short, cooper cannot be leached completely, which affects the cooper recovery. In order to study the effect of leaching time on the copper leaching, $1 \mathrm{~h}, 2 \mathrm{~h}, 3 \mathrm{~h}$ and $4 \mathrm{~h}$ were tested. The liquid-solid ratio and the ore to sulfuric acid weight ratio were 4:1 and 1:0.4, respectively. The leaching temperature was $25^{\circ} \mathrm{C}$, the shaking speed was $140 \mathrm{r} / \mathrm{min}$. Leaching results of different leaching time are shown in Fig .3.

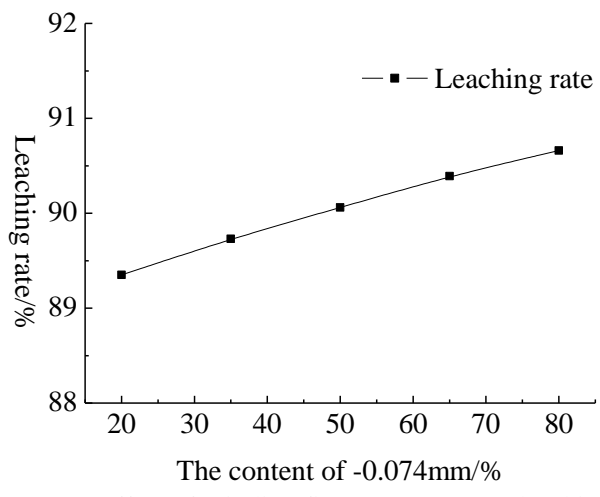

Figure 2. Effect of grinding fineness on copper leaching

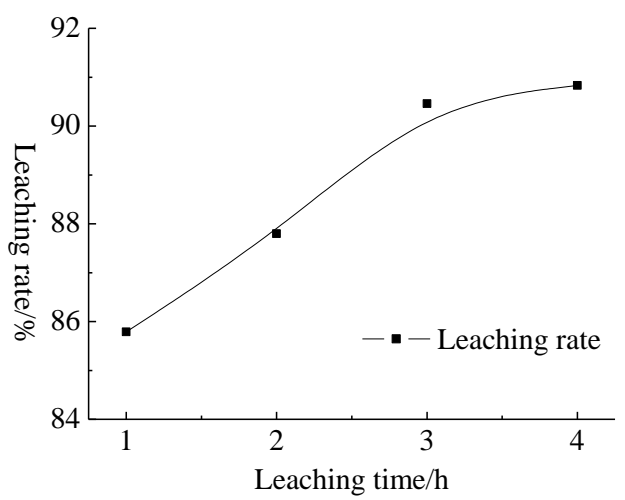

Figure 3. Leaching rate of copper under different leaching time

It can be seen from Fig .3 that copper leaching rates constantly increase with increasing of time. Initially the increasing is rapid, then slow. Leaching time increased from $2 \mathrm{~h}$ to $3 \mathrm{~h}$, the leaching rate increased by $2.66 \%$. When the leaching time was $4 \mathrm{~h}$, contrasting with $90.46 \%$ leaching rate of $3 \mathrm{~h}$, only the leaching rate of $90.83 \%$ was obtained. Most of the copper oxide had been leached, 
therefore, the leaching time of $3 \mathrm{~h}$ suits to the copper ore.

\section{Effect of liquid-solid ratio}

The liquid-solid ratio effects on the reagent dosage, leaching time and equipment volume. If liquid-solid ratio increases, the reagent consumption is bigger, leaching time is longer, leaching equipment volume is bigger. If liquid-solid ratio has barely influence on the leaching rate, low-liquid-solid ratio is optimal. In consequence, the tests were carried out with the different liquid-solid ratio. The followings are the test conditions that the leaching time was $3 \mathrm{~h}$, the ore to sulfuric acid weight ratio was 1:0.4, the leaching temperature was $25^{\circ} \mathrm{C}$, the shaking speed was $140 \mathrm{r} / \mathrm{min}$. The liquid-solid ratio decreased from 5:1 to $2: 1$. The results of effect of liquid-solid ratio on copper leaching are shown in Fig .4.

The conclusion can be obtained through Fig .4 that increasing the liquid-solid ratio result in the improvement of leaching rate of copper. When the liquid-solid ratio was $4: 1$, the highest leaching rate $91.53 \%$ was obtained. To increase the liquid-solid ratio to $5: 1$, the leaching rate reduced to $86.79 \%$. Excessive liquid-solid ratio is harmful to improve leaching rate. In order to achieve the best effect of leaching, the proper liquid-solid ratio be determined to be $4: 1$.

\section{E. Effect of the ore to sulfuric acid ratio}

Sulfuric acid has certain corrosivity. If excessive sulfuric acid remains in leachate, it will damage the test equipment and pollute the environment, even cause harm to human beings. Insufficient dosage of sulfuric acid will affect the leaching rate. In the leaching test, dosage of sulfuric acid should exceed the theoretical value that is calculated by the chemical reaction equation. What's more, after the reaction, the amount of remaining sulfuric acid should be as less as possible. The leaching time of $3 \mathrm{~h}$, the liquid-solid ratio of $4: 1$, the leaching temperature of $25^{\circ} \mathrm{C}$ and the shaking speed of $140 \mathrm{r} / \mathrm{min}$ were identified as the constant test conditions. The ore to sulfuric acid ratio decreased from 1:0.2 to 1:0.5. The results are shown in Fig .5.

It is shown in Fig .5 that with the dosage of sulfuric acid increasing, the leaching rate gradually increased. The leaching rate reached its peak with the ore to sulfuric acid ratio of 1: 0.4. However, the leaching rate decreased sharply when the ore to sulfuric acid ratio was $1: 0.5$. Thus, 1:0.4 is considered to be the optimum ore to sulfuric acid ratio.

Finally, via a large number of leaching experiments, it is found the best test conditions that the liquid-solid ratio of 4: 1 , the ore to sulfuric acid weight ratio of $1: 0.4$, the temperature of $25^{\circ} \mathrm{C}$, the shaking speed of $140 \mathrm{r} / \mathrm{min}$ and leaching time of $4 \mathrm{~h}$ were applied, respectively. Under the best conditions, the leaching rate of copper reached up to $90 \%$.

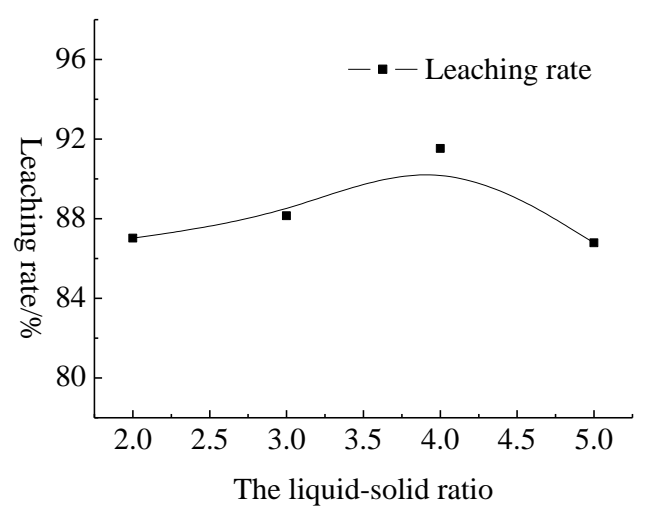

Figure 4. Leaching rate of copper under different ratio of liquid to solid ratio

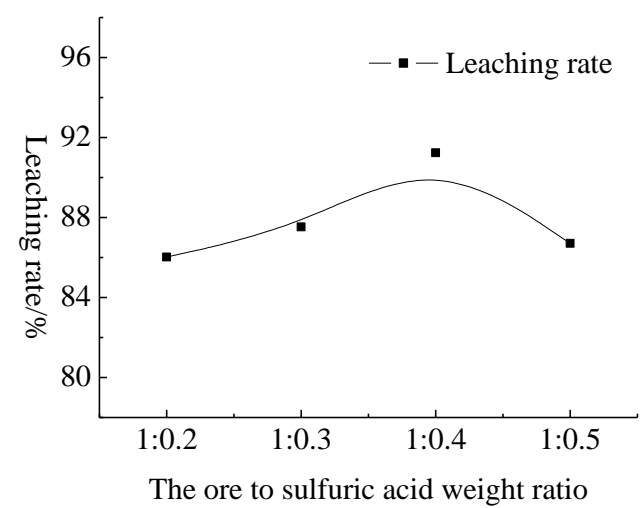

Figure 5. Leaching rate of copper under different ratio of ore to sulfuric acid

\section{TESTS ON OPTIMUM CONDITIONS AND VERIFICATION EXPERIMENTS}

Through the above experiments, the optimum conditions were researched. The grinding was invalid, the ore after crushing directly was used to leach. The liquid-solid ratio was $4: 1$, the ore to sulfuric acid ratio was 1: 0.4 , the leaching temperature was $25{ }^{\circ} \mathrm{C}$, the shaking speed was $140 \mathrm{r} / \mathrm{min}$ and the leaching time was $3 \mathrm{~h}$. In order to verify the test stability and ensure the test data with good reproducibility, four verification experiments were performed, under optimal conditions. The results are shown in Table 3. Assaying the combined leachate of four experiments, the results are shown in Table 4.

TABLE III RESULTS OF TEST AT BEST CONDITIONS

\begin{tabular}{ccccc}
\hline Test number & 1 & 2 & 3 & 4 \\
\hline $\begin{array}{c}\text { Leaching rate of } \\
\text { copper /\% }\end{array}$ & 90.93 & 91.23 & 90.58 & 91.01 \\
\hline $\begin{array}{c}\text { Copper grade of } \\
\text { leaching residue/\% }\end{array}$ & 0.22 & 0.21 & 0.23 & 0.21 \\
\hline
\end{tabular}


TABLE IV INGREDIENT OF LEACHING LIQUID

\begin{tabular}{ccccc}
\hline Element & $\mathrm{Cu}$ & $\mathrm{Zn}$ & $\mathrm{Fe}$ & $\mathrm{Sb}$ \\
\hline Content $/ \%$ & 91.79 & 2.31 & 5.64 & 0.26 \\
\hline
\end{tabular}

It can be seen from table 5 and Table 6 that all the conditions were optimum. Finally, the leaching rate of copper exceeded $90 \%$. The copper content of leaching residue was less than $0.28 \%$. Copper has been effectively recovered.

\section{CONCLUSIONS}

The oxidation rate of the oxide ore reach up to86.36\%, and copper oxide exists in the form of malachite, azurite and cuprite. The chemical composition of the ore is relatively simple, so that the oxide ore is easy to be leached. Whether using grinding, the leaching rate of copper is almost no difference under the same conditions. From an economic point of view, the ore without grinding, size is $-1 \mathrm{~mm}$, is used to leach directly. Through a series of leaching tests, the optimal conditions of leaching of the copper oxide were researched: the liquid-solid ratio is $4: 1$, the ore to sulfuric acid ratio is 1 : 0.4 , the leaching temperature is $25{ }^{\circ} \mathrm{C}$, the shaking speed is $140 \mathrm{r} / \mathrm{min}$ and the leaching time is $3 \mathrm{~h}$. Finally, copper leaching rate of more than $90 \%$ is obtained. After leaching, the component of leachate included $\mathrm{Cu} 91.79 \%$, Zn $2.31 \%$, Fe 5.64\%, Sb0.26\%.The impurities are little, copper was recovered effectively.

\section{ACKNOWLEDGMENT}

The authors are grateful to the funding for this study from the Applied Fundamental Research of Yunnan Province (No.2013FZ023).

\section{REFERENCES}

[1] Jianrong $\mathrm{Li}$, Huairen $\mathrm{Li}$, Tianjian Xie, Houwen Zhang and Hongling Wu, "Study on Preparation of Copper Sulfate from
Copper Slag with Oxygen", Nonferrous Metals (Extractive

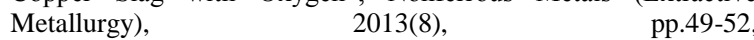
doi:10.3969/j.issn.1007-7545.2013.08.015

[2] Xi Yong, Wu Aixiang, Zhu Zhigen and Jiang Huaichun, Study on Correlation between Particle Size of Oxidized Copper Ore, Metal Mine, 2006(9), pp. 49-52.

[3] E.A. Oraby and J.J. Eksteen, The selective leaching of copper from a gold-copper concentrate in glycine solutions, Hydrometallurgy, Vol. 150, 2014, pp.14-19.

[4] Lambert. F, et al. Copper leaching from waste electric cables by biohydrometallurgy. Miner. Eng. (2015) http://dx.doi.org/10.1016/j.mineng.2014.12.029

[5] Kostudis, S, et al. Leaching of copper from Kupferschiefer by glutamic acid and heterotrophic bacteria. Miner. Eng. (2015), http://dx.doi.org/10.1016/j.mineng.2014.12.035

[6] Arslan, F, et al. Studies on leaching of massive rich copper ore in acidic ferric sulfate solutions, Scand. J. Metall., vol.33,2004, pp. 6-14, doi: 10.1111/j.1600-0692.2004.00662.x

[7] Debora M. de Oliveira, Luis G.S. Sobral, Gregory J. Olson and Susan B. Olson, Acid leaching of a copper ore by sulphur-oxidizing microorganisms, Hydrometallurgy, Vol. 147-148, 2014, pp.223-227.

[8] H.R. Watlinga, D.W. Shiersa, J. Lia, N.M. Chapmana and G.B Douglasb, Effect of water quality on the leaching of a low-grade copper sulfide ore, Mineral Engineering, vol.58, 2014, pp.39-51.

[9] S. Vafaeiana, M. Ahmadiana, B. Rezaeib, Sulphuric acid leaching of mechanically activated copper sulphidic concentrate, Mineral Engineering, vol.24, 2011, pp.1713-1716.

[10] S.M. Javad Koleinia, Valeh Aghazadeha, Åke Sandström, Acidic sulphate leaching of chalcopyrite concentrates in presence of pyrite, Mineral Engineering, vol.24, 2011, pp.381-386.

[11] Jinxiu Huang, Mengjun Chen, Haiyan Chen, Shu Chen and Quan Sun, Leaching behavior of copper from waste printed circuit boards with Brønsted acidic ionic liquid, Waste Management, vol.34, 2014, pp. 483-488.

[12] Jianming Lu, David Dreisinger, Copper leaching from chalcopyrite concentrate in $\mathrm{Cu}(\mathrm{II}) / \mathrm{Fe}$ (III) chloride system, Minerals Engineering, vol. 45, 2013, pp. 185-190.

[13] Jorcy Y. Trujillo, Luis A. Cisternas, Edelmira D. Gálvez, Mario E. Mellado, Optimal design and planning of heap leaching process. Application to copper oxide leaching, Chemical Engineering Research and Design, vol. 92, 2014, pp. 308-317. 